\title{
(2) OPEN ACCESS \\ Visual acuity outcomes after cataract surgery in type 2 diabetes: the Action to Control Cardiovascular Risk in Diabetes (ACCORD) study
}

\author{
Debora Lee, ${ }^{1}$ Elvira Agron, ${ }^{1}$ Tiarnan Keenan, ${ }^{1}$ James Lovato, ${ }^{2}$ Walter Ambrosius, ${ }^{2}$ \\ Emily Y Chew 1 , , ${ }^{1}$ On behalf of the ACCORD Eye Study Research Group
}

\begin{abstract}
- Additional supplemental material is published online only. To view, please visit the journal online (http://dx.doi. org/10.1136/bjophthalmol2020-317793)
\end{abstract}

'Division of Epidemiology and Clinical Applications, National Eye Institute, Bethesda,

Maryland, USA

2Department of Statistics, Wake Forest University Division of Public Health Sciences, WinstonSalem, North Carolina, USA

Correspondence to Dr Emily Y Chew, National Institutes of Health, Bethesda, MD 20892, USA:

echew@nei.nih.gov

Received 22 August 2020 Accepted 23 May 2021
D) Check for updates

(c) Author(s) (or their employer(s)) 2021. Re-use permitted under CC BY-NC. No commercial re-use. See rights and permissions. Published by BMJ.

To cite: Lee $\mathrm{D}$, Agron $\mathrm{E}$, Keenan T, et al.

Br J Ophthalmol Epub ahead of print: [please include Day Month Year]. doi:10.1136/ bjophthalmol-2020-317793

\section{ABSTRACT}

Aims To evaluate visual acuity (VA) outcomes of cataract surgery, and factors associated with good visual outcomes, among a population with diabetes.

Methods Participants with type 2 diabetes enrolled in The Action to Control Cardiovascular Risk in Diabetes (ACCORD) study and ACCORD-eye substudy. 1136 eyes of 784 ACCORD participants receiving cataract surgery during follow-up (2001-2014) were included. Of these, 362 eyes had fundus photographs gradable for diabetic retinopathy. The main outcome measure was the achievement of postoperative VA of 20/40 or better.

Results In the sample of 1136 eyes, 762 eyes (67.1\%) achieved good visual outcome of 20/40 or better. Factors predictive of good visual outcome were higher level of educational attainment (college vs some high school, OR $2.35(95 \% \mathrm{Cl} 1.44$ to 3.82$))$, bilateral cataract surgery (OR 1.55 (1.14 to 2.10)) and preoperative VA (20/20 or better vs worse than 20/200, OR 10.59 (4.07 to 27.54)). Factors not significantly associated $(p>0.05)$ included age, sex, race, smoking, diabetes duration, blood pressure, lipid levels and haemoglobin $\mathrm{A} 1 \mathrm{C}(\mathrm{HbA1C})$. In the subsample of 362 eyes, absence of diabetic retinopathy was associated with good visual outcome (OR 1.73 (1.02 to 2.94)).

Conclusion Among individuals with diabetes, twothirds of eyes achieved good visual outcome after cataract surgery. Notable factors associated with visual outcome included preoperative VA and diabetic retinopathy, but not $\mathrm{HbA} 1 \mathrm{C}$, underscoring that while certain ocular measures may help evaluate visual potential, systemic parameters may not be as valuable. Sociodemographic factors might also be important considerations. Although the current visual prognosis after cataract surgery is usually favourable, certain factors still limit the visual potential in those with diabetes.

\section{INTRODUCTION}

Cataract extraction is one of the most frequently performed ambulatory procedures, and its incidence continues to increase. ${ }^{12}$ The prevalence of diabetes mellitus has also risen and is projected to reach $33 \%$ of the US adult population by $2050 .^{3}$ Individuals with diabetes have an increased risk of cataract development and subsequent need for cataract surgery. However, in older publications principally from the 1990s, the visual outcomes after cataract surgery were reported to be less favourable in the presence of diabetes. ${ }^{4-7}$ Commonly cited reasons for worse visual outcomes included pre-existing diabetic retinopathy and macular oedema. ${ }^{89}$

In recent years, major developments have occurred in cataract surgery, the treatment of diabetic retinopathy and the management of diabetes. Newer surgical techniques (eg, smallincision phacoemulsification) have been associated with improved postoperative outcomes. ${ }^{9}$ Superior imaging modalities and modern laser treatments have enhanced the management of diabetic retinopathy. ${ }^{10} 11$ Recommendations for tighter glycaemic and blood pressure control have decreased the risk of diabetic complications. ${ }^{12} 13$ These advances may have improved the potential for good visual outcomes after cataract surgery in individuals with diabetes. However, very few large-scale studies have evaluated the visual outcomes of people with diabetes after cataract surgery.

The Action to Control Cardiovascular Risk in Diabetes (ACCORD), a randomised controlled trial studied the effects of various medical interventions on cardiovascular outcomes in participants with type 2 diabetes. In the ACCORD population, the current study aimed to (1) analyse visual outcomes after cataract surgery and (2) identify predictors of good visual outcome in individuals with diabetes.

\section{MATERIALS AND METHODS}

This was a retrospective case-control study of patients enrolled in the ACCORD and ACCORD-eye substudy. The main study and ancillary eye study ( ClinicalTrials.gov identifiers NCT00000620 and NCT00542178) protocols were approved by the institutional review boards at their respective coordinating centres and each clinical centre. The study was conducted in accordance with the principles of the Declaration of Helsinki and complied with the Health Insurance Portability and Accountability Act. Signed informed consent was obtained from each participant for all trials.

\section{Study population}

ACCORD Study (2001-2009). The study designs of the ACCORD and ACCORD-eye studies have been described previously. ${ }^{14}{ }^{15}$ In brief, the ACCORD study was a double $2 \times 2$ factorial, multicentre, randomised clinical trial studying the effects of intensive glycaemic control, intensive blood pressure control and/or treatment of dyslipidaemia with fenofibrate on cardiovascular events in patients with type 2 diabetes. From January 2001 to October 
2005, 10251 participants with type 2 diabetes and at high risk for cardiovascular disease (CVD) were recruited at 77 clinical centres (aggregated within seven networks) across the US and Canada.

The ACCORD study participants were randomised to either intensive or standard glycaemic control (target haemoglobin A1C (HbA1C) $<6.0 \%$ vs 7.0\%-7.9\%). Of the 10251 participants in the ACCORD study, 4733 participants were additionally randomised to either intensive or standard blood pressure control (target systolic blood pressure $<120 \mathrm{~mm} \mathrm{Hg}$ vs $<140 \mathrm{~mm}$ $\mathrm{Hg}$ ). The remaining 5518 participants were randomised to fenofibrate (to reduce triglycerides and increase high density lipoprotein-cholesterol) or placebo, in the context of effective LDL-cholesterol control with simvastatin. The ACCORD study primary outcome was the first occurrence of a major CVD event (ie, a nonfatal myocardial infarction, nonfatal stroke or death from a cardiovascular cause). In addition to clinical data regarding CVD, self-reported eye-related data including cataract surgery, neodymium-doped yttrium aluminum garnet laser capsulotomy, any retinopathy and photocoagulation/vitrectomy for diabetic retinopathy were documented at each annual study visit. Participants were asked only whether these events had occurred since their last annual study visit, and not the date on which each event had occurred. Visual acuity (VA) was assessed in the nonophthalmic study clinics at study baseline and every 2 years thereafter with a standardised VA chart (Early Treatment Diabetic Retinopathy Study (ETDRS) chart). Participants were instructed to bring their current glasses with them and were assessed for VA using current refractive correction (ie, presenting VA (PVA)) reflecting participants' true day-to-day vision.

ACCORD-Eye study (2003-2009). The ACCORD-Eye study investigated a subset of the ACCORD study participants for the effects of the three medical interventions on the progression of diabetic retinopathy. From October 2003 to March 2006, the ACCORD-Eye study recruited 3537 of the ACCORD study participants without a history of proliferative diabetic retinopathy (PDR) treated with laser photocoagulation or vitrectomy. Each clinical centre identified study ophthalmologists to conduct standardised eye examinations on all ACCORD Eye study participants at baseline and year 4 . These examinations included a VA measurement conducted by a staff member with the method customarily used in that office using the patient's glasses; if VA was worse than 20/40, a pinhole was added. Colour fundus photographs of seven standard stereoscopic fields were also obtained and graded by masked evaluators at the Fundus Photograph Reading Center (University of Wisconsin, Madison) for the presence and severity of diabetic retinopathy. The severity of diabetic retinopathy was graded using the ETDRS Final Diabetic Retinopathy Severity Scale for individual eyes, and categorised into the following five levels using the International Clinical Diabetic Retinopathy Severity scale: none $(<20)$, mild non-PDR (NPDR) (20), moderate NPDR (35-47), severe NPDR (53) and $\operatorname{PDR}(\geq 60)$.

\section{Study sample}

The inclusion criteria for the current analysis were eyes that (1) underwent cataract surgery during the ACCORD study follow-up and (2) had both a preoperative VA recorded within 2 years prior to surgery and a postoperative VA recorded within 2 years after surgery. Eyes that were pseudophakic or aphakic at baseline were excluded. The preoperative and postoperative VA used were the closest documented VA prior to and following cataract surgery, respectively.
Within the study sample, a subset of eyes received fundus photographs graded for diabetic retinopathy (ie, eyes of ACCORD-Eye participants). All analyses conducted in this subsample included data on diabetic retinopathy, which was categorised by presence/absence and severity level.

\section{Primary outcome}

In addition to analysing visual outcomes after cataract surgery, the current study aimed to examine the sociodemographic, systemic and ocular factors associated with a primary outcome of good visual outcome after cataract surgery. Good visual outcome was defined as postoperative VA of $20 / 40$ or better.

\section{Statistical analysis}

Repeated measures logistic regression was used to evaluate the association of the covariates with postoperative VA $\geq 20 / 40$. The unit of analysis was the eye. Because some participants contributed both eyes to the analysis, the exchangeable correlation structure was used to account for correlation between both eyes of a person.

A list of covariates (online supplemental eTable 1) was examined for potential inclusion in the final model by means of the variable selection approach described herein. Cross-tabulation analyses were initially conducted to compare proportions and means for variables between the two groups, leading to the exclusion of several variables, particularly those with very low frequencies. Next, a series of univariate analyses were performed to examine the associations between the narrowed list of variables and the primary outcome. Those variables screened at $\mathrm{p}<0.15$ were then used in the selection of a final multivariate regression model. ${ }^{16}$ In a multistep process, variables were entered or removed from the model by comparing the QIC $\mu$ (quasi likelihood under the independence) between the model with the variable with the model without the variable. ${ }^{16}$ The variables age (at cataract surgery) and sex were included in all models. Self-reported data on the presence/absence of any retinopathy were not included because fundus photograph data were thought to be more accurate (see next paragraph). The analyses were performed with variables obtained at study baseline, with exception of age at cataract surgery, and preoperative and postoperative VA.

This multivariate regression model was then applied to the subsample of eyes that received fundus photographs. In this analysis, the variable diabetic retinopathy (categorised by presence/absence) was added to the list of covariates, after which the associations between the covariates and the primary outcome were reevaluated. Analyses were conducted using SAS V.9.4 (SAS Institute, Cary, North Carolina, USA).

\section{RESULTS}

\section{Description of study sample}

From 2001 to 2009, the ACCORD study followed 10251 participants with type 2 diabetes at high risk for CVD for a median of 5.0 years (IQR 4.1-5.7). Of the 17774 eyes for which eye-related data and VA data were collected, 1816 eyes $(10.8 \%)$ underwent cataract surgery during follow-up and, after applying the inclusion criteria, 1136 (62.6\%) eyes of 784 participants remained in the sample for analysis. The demographic and clinical characteristics of the participants included in the analyses are shown in table 1 . The ocular characteristics of the eyes included in the analyses are shown in table 2. A total of 680 eyes of 474 participants were excluded from the study sample, and the demographic/clinical and ocular characteristics for these 


\begin{tabular}{|c|c|}
\hline Characteristic & $\begin{array}{l}\text { Overall } \\
(\mathrm{n}=784)\end{array}$ \\
\hline Age at randomisation, mean years $\pm S D$ & $65.6 \pm 6.3$ \\
\hline Male sex, n (\%) & $458(58.4)$ \\
\hline \multicolumn{2}{|l|}{ Race, n (\%) } \\
\hline White & $537(68.5)$ \\
\hline Black & $115(14.7)$ \\
\hline Hispanic & $47(6.0)$ \\
\hline Other & $85(10.8)$ \\
\hline \multicolumn{2}{|l|}{ Highest level of education, $\mathrm{n}(\%)$} \\
\hline Some high school & $120(15.3)$ \\
\hline High school graduate & $231(29.5)$ \\
\hline Some college & $253(32.3)$ \\
\hline College graduate or more & $180(23.0)$ \\
\hline \multicolumn{2}{|l|}{ Clinical centre network, n (\%) } \\
\hline Canada & $131(16.7)$ \\
\hline Western & $100(12.8)$ \\
\hline Minnesota/lowa & $113(14.4)$ \\
\hline Ohio/Michigan & $146(18.6)$ \\
\hline Northeastern & $77(9.8)$ \\
\hline Southeastern & 109 (13.9) \\
\hline Veterans affairs & $108(13.8)$ \\
\hline Insurance coverage, n (\%) & $715(91.2)$ \\
\hline \multicolumn{2}{|l|}{ Smoking status, n (\%) } \\
\hline Current & $66(8.4)$ \\
\hline Former & $402(51.3)$ \\
\hline Never & $316(40.3)$ \\
\hline Cardiovascular disease, $\mathrm{n}(\%)$ & $282(36.0)$ \\
\hline $\mathrm{HbA} 1 \mathrm{C}$, mean $\% \pm \mathrm{SD}$ & $8.3 \pm 1.0$ \\
\hline Diabetes duration, mean years $\pm \mathrm{SD}$ & $16.3 \pm 8.0$ \\
\hline \multicolumn{2}{|l|}{ Medications, n (\%) } \\
\hline Oral hypoglycaemic agents & $628(80.1)$ \\
\hline Insulin & $368(46.9)$ \\
\hline Aspirin & $477(60.8)$ \\
\hline Cardiovascular agents & $80(10.2)$ \\
\hline Lipid-lowering agents & $563(71.8)$ \\
\hline Bilateral cataract surgery, $n(\%)$ & $500(63.8)$ \\
\hline
\end{tabular}

HbA1C, haemoglobin A1C.

participants and eyes are also shown in online supplemental eTables 2 and 3, respectively. Overall, individuals in the current study reported undergoing cataract surgery at a median time of 3.0 years (IQR 2.0-4.4) after randomisation. The median time from measurement of preoperative VA to report of surgery was 1.3 years (IQR 1.0-1.8), and the median time from report of

\begin{tabular}{lc}
\hline Table 2 & \multicolumn{1}{c}{ Baseline ocular characteristics of eyes in the study sample } \\
\hline Characteristic & $\begin{array}{l}\text { Overall } \\
(\mathbf{n}=1136)\end{array}$ \\
\hline Photocoagulation/vitrectomy, $\mathrm{n}(\%)$ & $161(14.2)$ \\
\hline Other eye surgery, $\mathrm{n}(\%)$ & $57(5.0)$ \\
Pre-operative VA, $\mathrm{n}(\%)$ & $106(9.3)$ \\
$<20 / 200$ & $505(44.5)$ \\
\hline$<20 / 40-20 / 200$ & $483(42.5)$ \\
\hline$<20 / 20-20 / 40$ & $42(3.7)$ \\
\hline$\geq 20 / 20$ &
\end{tabular}

$\mathrm{VA}$, visual acuity.

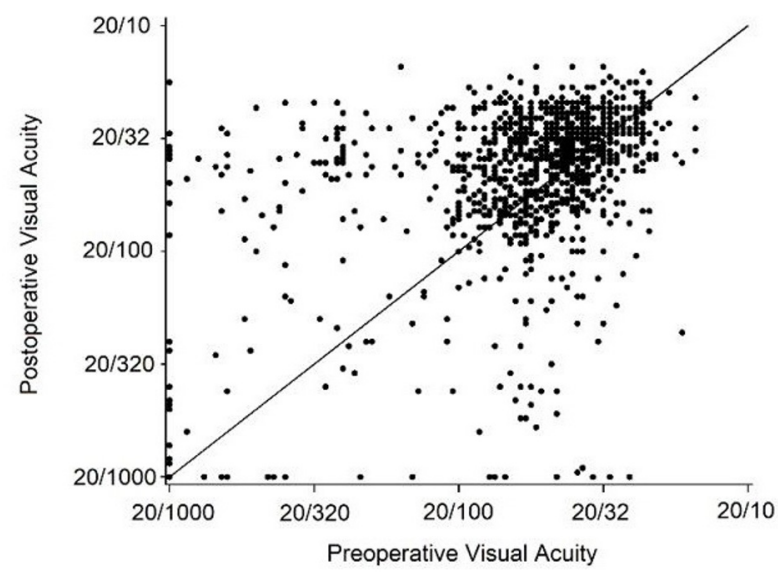

Figure 1 Visual acuity scores before and after cataract surgery of eyes in the study sample ( $n=1136$ eyes).

surgery to measurement of postoperative VA was 0.6 years (IQR $0.0-1.0)$.

Of the overall sample, 362 eyes $(31.9 \%)$ of 251 participants received fundus photographs gradable for diabetic retinopathy as part of the ACCORD-eye study. In this subsample, 179 eyes $(49.4 \%)$ had no diabetic retinopathy, 50 eyes $(13.8 \%)$ had mild NPDR, 124 eyes (34.3\%) had moderate NPDR, 3 eyes $(0.8 \%)$ had severe NPDR and 6 eyes $(1.7 \%)$ had PDR. Among the ACCORD-eye subsample, there was a statistically significant difference between mean $( \pm S D)$ presenting and pinhole VA scores (71.4 \pm 11.8 letters (Snellen equivalent 20/40) and $74.5 \pm 10.2$ letters $(20 / 30), p<0.001)$. However, this three-letter difference is within the measurement error and is not clinically meaningful.

\section{Visual outcomes in individuals with diabetes}

Overall, 762 eyes (67.1\%) achieved a good visual outcome (ie, postoperative VA $\geq 20 / 40$ ). The distribution of ocular variables of eyes that did versus did not achieve good visual outcomes are shown in online supplemental eTable 4. Among the subsample of eyes that received fundus photographs, 265 eyes (73.2\%) achieved a good visual outcome. The distributions of preoperative and postoperative VA (and their relationships to each other at the individual eye level) for the overall sample are depicted in figure 1 . The distributions according to severity of diabetic retinopathy for the subsample of eyes that received fundus photographs are shown in figure 2; they are also shown in a stratified tabular form in table 3 . For the overall sample, the mean change $( \pm \mathrm{SD})$ in VA score after cataract surgery was $+3.7 \pm 18.4$ letters. Analysis of the distribution showed 535 eyes (19.5\%) had $\geq 15$ letter improvement, 333 eyes (12.1\%) had $14-10$ letter improvement, 426 eyes $(15.5 \%)$ had $9-5$ letter improvement, 791 eyes $(28.8 \%)$ had \pm 4 letter change, 268 eyes $(9.8 \%)$ had 5-9 letter worsening, 147 eyes $(5.3 \%)$ had 10-14 letter worsening, and $248(9.0 \%)$ had $\geq 15$ letter worsening.

\section{Predictors of good visual outcome}

The results of the multivariate repeated measures logistic regression are shown in table 4. The factors associated with good visual outcome were highest level of education (reference, some high school; highest, college graduate, OR 2.35 (95\% CI 1.44 to 3.82)), clinical centre network (reference, Northeastern USA; highest, Veterans Affairs, OR 3.46 (95\% CI 1.90 to 6.28)), preoperative VA (reference, <20/200; highest, 20/20+, OR 10.59 (95\% CI 4.07 to 27.54$)$ ) and bilateral cataract surgery (OR 1.55 (95\% CI 1.14 

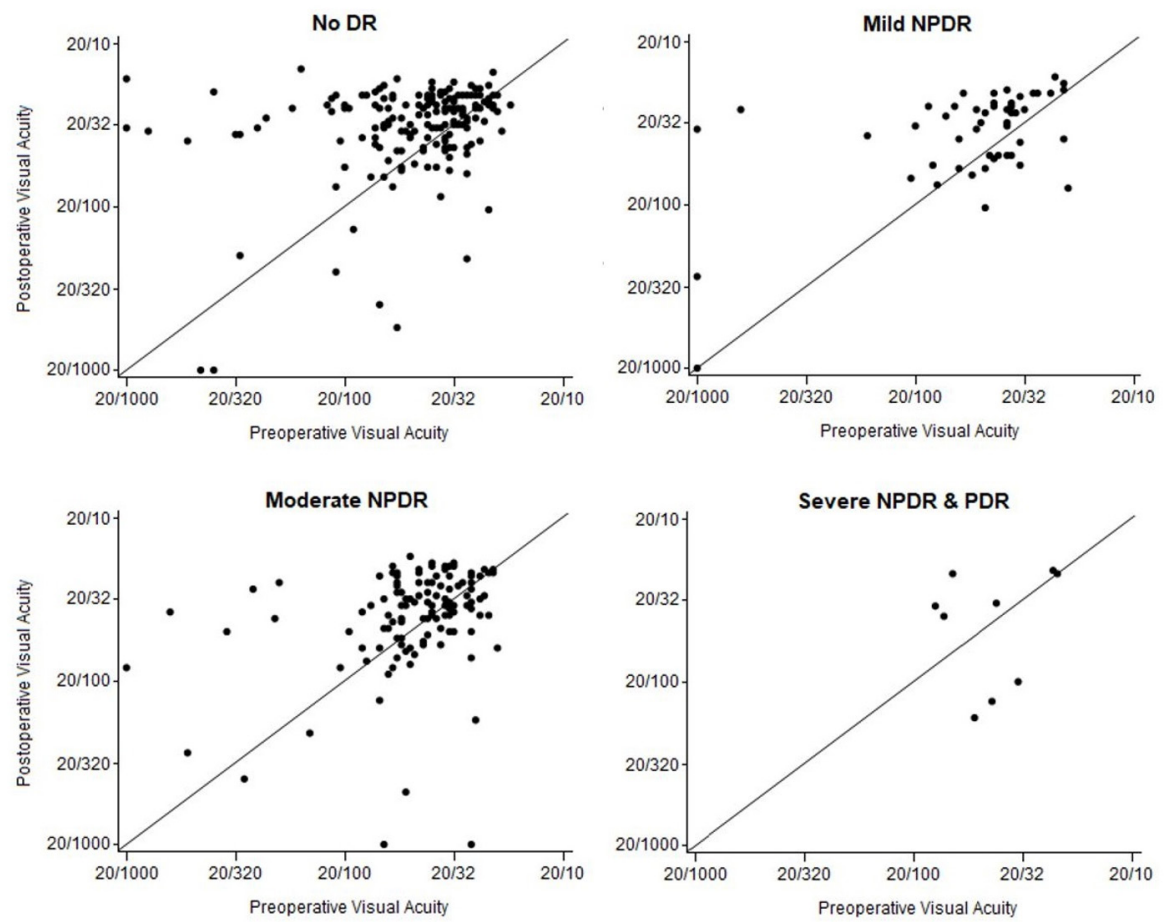

Figure 2 Visual acuity scores before and after cataract surgery in the subsample of eyes that received fundus photographs ( $n=362$ eyes), according to severity of diabetic retinopathy. PDR, proliferative diabetic retinopathy; NPDR, non-PDR.

to 2.10)). The variables race, insurance status, diabetes duration, HbA1C, lipid levels, blood pressure, insulin, lipid-lowering agents, time of cataract surgery (days from randomisation) and randomisation to medical treatments (eg, intensive glycaemic control) were not significant during the model selection.

The results of the multivariate repeated measures logistic regression for the subsample of eyes that received fundus photographs are shown in table 5. In this analysis, the factors associated with good visual outcome remained similar except for the inclusion of diabetic retinopathy and exclusion of clinical centre network from the model. Analysis by diabetic retinopathy severity did not show clear association between level of diabetic retinopathy and good visual outcome (reference, none; mild NPDR, OR 0.60 (95\% CI 0.30 to 1.23$), \mathrm{p}=0.16$; moderate NPDR, OR 0.58 (0.33 to 1.01 ), $\mathrm{p}=0.05$; severe NPDR or PDR, OR 0.40 (0.09 to 1.85$), \mathrm{p}=0.24)$.

\section{DISCUSSION}

This is one of the largest studies to assess VA outcomes in people with diabetes undergoing cataract surgery. Furthermore, this study provides an updated benchmark of the prevalence of good visual outcome after cataract surgery in a contemporary

Table 3 Visual acuity scores before and after cataract surgery among the subsample of eyes that received fundus photographs $(n=362)$, according to diabetic retinopathy severity

\begin{tabular}{lll}
\hline DR severity & Preoperative VA & Postoperative VA \\
\hline None $(n=179)$ & $65.4 \pm 16.5(20 / 50)$ & $74.1 \pm 14.2(20 / 33)$ \\
Mild $(n=50)$ & $62.7 \pm 20.4(20 / 58)$ & $71.1 \pm 15.5(20 / 38)$ \\
Moderate $(n=124)$ & $65.9 \pm 14.6(20 / 50)$ & $69.6 \pm 15.6(20 / 40)$ \\
Severe or PDR $(n=9)$ & $67.9 \pm 10.3(20 / 46)$ & $66.7 \pm 17.7(20 / 48)$ \\
Total $(n=362)$ & $65.2 \pm 16.3(20 / 50)$ & $72.0 \pm 15.1(20 / 36)$ \\
\hline
\end{tabular}

The results are listed as mean \pm SD VA letter score (Snellen equivalent).

$\mathrm{DR}$, diabetic retinopathy; PDR, proliferative diabetic retinopathy; VA, visual acuity. population with diabetes. Finally, the wealth of data on sociodemographic, systemic and ocular characteristics allows for an extensive investigation of predictors of good visual outcome after cataract surgery in diabetes.

Table 4 Predictors of good visual outcome after cataract surgery in multivariate analysis of eyes in the study sample

\begin{tabular}{lcc}
\hline Characteristic & OR (95\% Cl) & P value \\
\hline Age at cataract surgery (per year) & $1.00(0.97$ to 1.02$)$ & 0.91 \\
\hline Male sex & $0.94(0.69$ to 1.27$)$ & 0.68 \\
\hline Highest level of education & & $0.006^{*}$ \\
\hline Some high school & 1.00 & \\
\hline High school graduate & $1.80(1.17$ to 2.76$)$ & 0.008 \\
\hline Some college & $1.66(1.07$ to 2.57$)$ & 0.03 \\
\hline College graduate or more & $2.35(1.44$ to 3.82$)$ & $<0.001$ \\
\hline Clinical centre network & & $0.001^{*}$ \\
\hline Northeastern US & 1.00 & \\
\hline Canada & $1.72(0.99$ to 2.97$)$ & 0.05 \\
\hline Western US & $2.16(1.22$ to 3.84$)$ & 0.09 \\
\hline Minnesota/lowa & $2.93(1.60$ to 5.35$)$ & $<0.001$ \\
\hline Ohio/Michigan & $2.25(1.31$ to 3.86$)$ & 0.003 \\
\hline Southeastern US & $1.69(0.96$ to 2.99$)$ & 0.07 \\
\hline Veterans Affairs & $3.46(1.90$ to 6.28$)$ & $<0.001$ \\
\hline Preoperative VA & & $<0.001^{*}$ \\
\hline$<20 / 200$ & 1.00 & 0.03 \\
\hline$<20 / 40-20 / 200$ & $1.65(1.05$ to 2.59$)$ & $<0.001$ \\
\hline$<20 / 20-20 / 40$ & $4.29(2.69$ to 6.83$)$ & $<0.001$ \\
\hline$\geq 20 / 20$ & $10.59(4.07$ to 27.54$)$ & 0.005 \\
\hline Bilateral cataract surgery & $1.55(1.14$ to 2.10$)$ & \\
\hline * Overall p-values calculated for categorical variables with $>2$ levels. & \\
VA, visual acuity. & & \\
\hline
\end{tabular}

Lee D, et al. Br J Ophthalmol 2021;0:1-7. doi:10.1136/bjophthalmol-2020-317793 
Table 5 Predictors of good visual outcome after cataract surgery in multivariate analysis in the subsample of eyes that received fundus photographs.

\begin{tabular}{lll}
\hline Characteristic & OR $(95 \% \mathrm{Cl})$ & P-value \\
\hline Age at cataract surgery (per year) & $0.97(0.93$ to 1.01$)$ & 0.17 \\
\hline Male sex & $1.20(0.69$ to 2.07$)$ & 0.53 \\
$\begin{array}{l}\text { Highest level of education } \\
\quad \text { Some high school }\end{array}$ & 1.00 & $0.09^{*}$ \\
\hline $\begin{array}{l}\text { High school graduate } \\
\text { Some college }\end{array}$ & $2.26(1.09$ to 4.69$)$ & 0.03 \\
\hline $\begin{array}{l}\text { College graduate or more } \\
\text { Preoperative VA }\end{array}$ & $2.28(1.10$ to 4.72$)$ & 0.03 \\
\hline $\begin{array}{l}<20 / 200 \\
\quad<20 / 40-20 / 200\end{array}$ & $1.84(0.86$ to 3.91$)$ & 0.11 \\
\hline$<20 / 20-20 / 40$ & $1.02(0.38$ to 2.70$)$ & $0.01^{*}$ \\
\hline $\begin{array}{l}\text { Bilateral cataract surgery } \\
\text { Diabetic retinopathy }\end{array}$ & $2.38(0.86$ to 6.59$)$ & 0.72 \\
\hline Presencet & $2.39(0.59$ to 9.72$)$ & 0.04 \\
\hline Absence & $1.78(1.03$ to 3.08$)$ & 0.23 \\
\hline
\end{tabular}

* Overall p-values calculated for categorical variables with $>2$ levels. tIncluded mild non-proliferative diabetic retinopathy (NPDR), moderate NPDR, severe NPDR, and proliferative diabetic retinopathy (PDR).

$\mathrm{VA}$, visual acuity.

\section{Good visual outcome in individuals with diabetes}

In the ACCORD study population, the rate of good visual outcome after cataract surgery was $67 \%$. This suggests that the current visual prognosis after cataract surgery is usually favourable in those with diabetes. Prior studies have reported 62\%-89\% of individuals with diabetes achieve a good visual outcome (ie, VA of 20/40 or better on Snellen, or the equivalent VA notation). ${ }^{4-7}$ 17-19 However, most of these studies contained samples of fewer than 200 eyes, dated back more than 15 years and occurred at a single institution. By contrast, this study represents a large sample of a more recent population from multiple centres across the USA and Canada.

Individuals in this cohort may presumably have benefitted from new clinical guidelines and medical developments, leading to better management of their disease and improved outcomes. ${ }^{10-132021}$ However, visual outcomes remained comparable to those previously reported, which may be due to several reasons. First, differences in the profile of patients, particularly in the prevalence and severity of diabetic retinopathy in each cohort, probably affected visual outcomes. ${ }^{22} 23$ The current and prior studies reported rates of diabetic retinopathy prevalence at $51 \%$ and 29\%-68\%, respectively, though higher prevalence did not always correspond with poorer outcomes. ${ }^{4-7}$ 17-19 Second, variation in factors related to cataract surgery (eg, surgical techniques) or postoperative care (eg, macular oedema management) may also be important. Third, while prior studies measured best-corrected VA (BCVA), this study measured PVA to better reflect day-to-day functional vision. Visual impairment from uncorrected refractive error is a common condition in the USA, with rates higher in certain populations, including those with diabetes. ${ }^{24}$ Despite advances in the refractive components of cataract surgery, differences between postoperative BCVA and PVA may remain if individuals in whom residual refractive error exists are left uncorrected.

In the context of these considerations, people with diabetes continue to achieve less favourable visual outcomes relative to the general population. Large national cataract surgery registries show that $84 \%-91 \%$ of patients overall achieve postoperative BCVA of $20 / 40$ or better, with this figure rising to around $95 \%$ in patients without ocular comorbidity. ${ }^{25} 26$ Given this, our study indicates a continuing need to investigate the population with diabetes receiving cataract surgery and factors associated with visual outcome.

\section{Predictors of good visual outcome}

Identifying factors associated with good visual outcome may help to predict VA after cataract surgery and to determine areas for further improvement. The current study investigates the role of several sociodemographic, systemic and ocular factors on visual outcomes in people with diabetes.

First, preoperative VA was a significant prognostic measure and may be valuable in the surgical evaluation for several reasons. Worse preoperative VA may indicate ocular comorbidities, either independent from (eg, amblyopia, macular or corneal disease) or as a secondary cause of (eg, anterior uveitis) cataract, that could limit visual potential after surgery. Reduced preoperative VA can also reflect a more advanced or dense cataract, which may increase the risk for intraoperative and postoperative complications (eg, capsular rupture, macular oedema) and impair postoperative VA. ${ }^{27}$ Additionally, lower preoperative PVA can indicate inadequately corrected refractive error and an individual who may, thus, be unable to obtain or less likely to wear updated eyeglasses even after surgery. ${ }^{29}$

In patients with diabetes, this study suggests that the presence or absence of diabetic retinopathy is particularly important for visual outcomes. The severity of diabetic retinopathy could also be important, though this study did not have a large enough sample size to detect any significant effect. Several factors may be involved in the role of diabetic retinopathy. Diabetic retinopathy may limit postoperative VA through preexisting pathology, specifically macular ischemia, diabetic macular oedema (DMO) and/or proliferative disease. In eyes with diabetic retinopathy, cataract surgery can additionally precipitate DMO and may accelerate diabetic retinopathy progression, though evidence for the latter is less clear with phacoemulsification than with extracapsular extraction. ${ }^{30-32}$ In evaluating the utility or timing of cataract extraction, these factors should be weighed against the benefits of better visualising the retina to monitor diabetic retinopathy.

In this study, systemic characteristics, notably $\mathrm{HbA} 1 \mathrm{C}$, were not significantly associated with achieving a good visual outcome. For individuals with diabetes, the issue of glycaemic control often raises concern due to delayed wound healing, increased infection and the risk for progression of diabetic retinopathy. ${ }^{123334}$ Consistent with prior reports, however, this study found that baseline HbA1C level was not a significant factor. ${ }^{22} 23$ Though long-term systemic glycaemic control remains essential in diabetes management, with respect to visual outcomes after cataract surgery, an effect independent from that of the resulting diabetic eye disease may be less significant.

For patients with diabetes, social determinants of health influence clinical outcomes including diabetic retinopathy. ${ }^{35}$ It may, thus, be important to consider the role of such factors for those undergoing cataract surgery. In the current study, visual outcomes were notably associated with clinical centre network and education level. These factors may serve as a proxy for socioeconomic status and be particularly significant in elucidating areas for improvement. For instance, among persons with diabetes and diabetic retinopathy, lower educational attainment has been linked to reduced access to and utilisation of eye care 
services. $^{35}{ }^{36}$ This is especially relevant for those undergoing cataract surgery, as easily correctable issues such as posterior capsular opacification and refractive error remain among the most common complications of cataract surgery. ${ }^{2637}$ A stronger emphasis on postoperative follow-up may be important in these individuals, and the impact of social factors on visual outcomes should not be overlooked.

\section{Limitations}

There are several limitations to this study. First, the retrospective design may limit the ability to adjust for unknown confounding factors. Second, the use of clinical trial data may reduce generalisability of the results as trial participants often have higher levels of educational attainment, access to care and healthier behaviours, relative to the general population. Third, the infrequency at which VA was measured led to variation in the time intervals between the report of surgery and VA measurements and subsequently in the effects of various factors on outcome during these periods. Fourth, the infrequency at which surgery was reported led to variation in the time intervals between the reporting of and actual date of surgery and further contributed to variation in the effects of these factors on outcome. Fifth, the use of PVA may limit direct comparisons of the results from this study against those that used BCVA, though we consider PVA to be an important measure in itself. Sixth, this study could not specifically investigate the effects of DMO or antivascular endothelial growth factor injections on postoperative VA; future studies are necessary for examining the extent to which these factors impact the ability to achieve a good visual outcome after cataract surgery.

\section{CONCLUSION}

Among individuals with diabetes, two-thirds of eyes achieved a good visual outcome of $20 / 40$ or better, after cataract surgery. Despite new clinical guidelines and medical developments, this rate remained comparable to prior reports and lower than the general population. Notable factors associated with visual outcomes included preoperative VA and diabetic retinopathy, but not $\mathrm{HbA1C}$, underscoring that while certain ocular measures may help to evaluate visual potential, systemic parameters may not be as valuable. Socioeconomic status and related issues may also be important considerations. Although the current visual prognosis after cataract surgery is usually favourable, certain factors still limit the visual potential in those with diabetes and continued efforts to improve visual outcomes are necessary.

Contributors DL, EA, TK, EC contributed to research design, data analysis and manuscript preparation of the study. JL and WA contributed to research design, data acquisition of the study, and manuscript preparation of the study. EC is the guarantor of the study.

Funding This work was supported by the intramural program funds and contracts (N01-HC-95178, N01-HC-95179, N01-HC-95180, N01-HC-95181, N01HC-95182, N01-HC-95183, N01-HC-95184, IAA-Y1-HC-9035, IAA-Y1-HC-1010 and HHSN268201100027C) from the National Heart, Lung, and Blood Institute of the National Institutes of Health $(\mathrm{NIH})$, with additional support from the National Institute of Diabetes and Digestive and Kidney Diseases, the National Institute on Aging, and the National Eye Institute. General clinical research centres provided support at many sites. We also acknowledge the support of the NIH Medical Research Scholars Program (DHL), a public-private partnership supported jointly by the NIH and contributions to the Foundation for the NIH from the Doris Duke Charitable Foundation (DDCF Grant number 2014194), the American Association for Dental Research, the Colgate-Palmolive Company, Genentech, Elsevier and other private donors.

Competing interests None declared.

Patient consent for publication Not required.
Provenance and peer review Not commissioned; externally peer reviewed.

Data availability statement Data may be obtained from a third party and are not publicly available. Action to Control Cardiovascular Risk in Diabetes (ACCORD)https://biolincc.nhlbi.nih.gov/studies/accord

Supplemental material This content has been supplied by the author(s). It has not been vetted by BMJ Publishing Group Limited (BMJ) and may not have been peer-reviewed. Any opinions or recommendations discussed are solely those of the author(s) and are not endorsed by BMJ. BMJ disclaims all liability and responsibility arising from any reliance placed on the content. Where the content includes any translated material, BMJ does not warrant the accuracy and reliability of the translations (including but not limited to local regulations, clinical guidelines, terminology, drug names and drug dosages), and is not responsible for any error and/or omissions arising from translation and adaptation or otherwise.

Open access This is an open access article distributed in accordance with the Creative Commons Attribution Non Commercial (CC BY-NC 4.0) license, which permits others to distribute, remix, adapt, build upon this work non-commercially, and license their derivative works on different terms, provided the original work is properly cited, appropriate credit is given, any changes made indicated, and the use is non-commercial. See: http://creativecommons.org/licenses/by-nc/4.0/.

\section{ORCID iD}

Emily Y Chew http://orcid.org/0000-0003-0999-9802

\section{REFERENCES}

1 Hall MJ, Schwartzman A, Zhang J, et al. Ambulatory surgery data from hospitals and ambulatory surgery centers: United States, 2010. Natl Health Stat Report 2017; 102:1-15.

2 Gollogly HE, Hodge DO, St Sauver JL, et al. Increasing incidence of cataract surgery: population-based study. J Cataract Refract Surg 2013;39:1383-9.

3 Boyle JP, Thompson TJ, Gregg EW, et al. Projection of the year 2050 burden of diabetes in the US adult population: dynamic modeling of incidence, mortality, and prediabetes prevalence. Popul Health Metr 2010;8:29.

4 Cunliffe IA, Flanagan DW, George ND, et al. Extracapsular cataract surgery with lens implantation in diabetics with and without proliferative retinopathy. $\mathrm{Br} J$ Ophthalmol 1991:75:9-12

5 Antcliff RJ, Poulson A, Flanagan DW. Phacoemulsification in diabetics. Eye 1996:10:737-41.

6 Somaiya MD, Burns JD, Mintz R, et al. Factors affecting visual outcomes after small-incision phacoemulsification in diabetic patients. J Cataract Refract Surg 2002;28:1364-71.

7 Wagner T, Knaflic D, Rauber M, et al. Influence of cataract surgery on the diabetic eye: a prospective study. Ger J Ophthalmol 1996;5:79-83.

8 Chew EY, Benson WE, Remaley NA, et al. Results after lens extraction in patients with diabetic retinopathy: early treatment diabetic retinopathy study report number 25 . Arch Ophthalmol 1999;117:1600-6.

9 Dowler JG, Hykin PG, Hamilton AM. Phacoemulsification versus extracapsular cataract extraction in patients with diabetes. Ophthalmology 2000;107:457-62.

10 Hee MR, Puliafito CA, Duker JS, et al. Topography of diabetic macular edema with optical coherence tomography. Ophthalmology 1998;105:360-70.

11 Blumenkranz MS, Yellachich D, Andersen DE, et al. Semiautomated patterned scanning laser for retinal photocoagulation. Retina 2006;26:370-6.

12 Diabetes Control and Complications Trial Research Group, Nathan DM, Genuth $\mathrm{S}$, et al. The effect of intensive treatment of diabetes on the development and progression of long-term complications in insulin-dependent diabetes mellitus. N Engl J Med 1993;329:977-86.

13 Tight blood pressure control and risk of macrovascular and microvascula complications in type 2 diabetes: UKPDS 38. UK prospective diabetes Study Group. BMJ 1998:317:703-13.

14 ACCORD Study Group, Buse JB, Bigger JT, et al. Action to control cardiovascular risk in diabetes (ACCORD) trial: design and methods. Am J Cardiol 2007;99:\$21-33.

15 Chew EY, Ambrosius WT, Howard LT, et al. Rationale, design, and methods of the action to control cardiovascular risk in diabetes eye study (ACCORD-EYE). Am J Cardiol 2007:99:S103-11.

16 Pan W. Akaike's information criterion in generalized estimating equations. Biometrics 2001:57:120-5

17 Borrillo JL, Mittra RA, Dev S, et al. Retinopathy progression and visual outcomes after phacoemulsification in patients with diabetes mellitus. Trans Am Ophthalmol Soc 1999;97:435-45

18 Dowler JG, Hykin PG, Lightman SL, et al. Visual acuity following extracapsular cataract extraction in diabetes: a meta-analysis. Eye 1995;9:313-7.

19 Henricsson M, Heijl A, Janzon L. Diabetic retinopathy before and after cataract surgery. Br J Ophthalmol 1996;80:789-93.

20 Michaelides M, Kaines A, Hamilton RD, et al. A prospective randomized trial of intravitreal bevacizumab or laser therapy in the management of diabetic macular edema (bolt study) 12-month data: report 2. Ophthalmology 2010;117:1078-86. 
21 Rossetti L, Chaudhuri J, Dickersin K. Medical prophylaxis and treatment of cystoid macular edema after cataract surgery. The results of a meta-analysis. Ophthalmology 1998; 105:397-405.

22 Ostri C, Lund-Andersen H, Sander B, et al. Phacoemulsification cataract surgery in a large cohort of diabetes patients: visual acuity outcomes and prognostic factors. J Cataract Refract Surg 2011;37:2006-12.

23 Liu L, Herrinton LJ, Alexeeff S, et al. Visual outcomes after cataract surgery in patients with type 2 diabetes. J Cataract Refract Surg 2019;45:404-13

24 Vitale $\mathrm{S}$, Cotch MF, Sperduto RD. Prevalence of visual impairment in the United States JAMA 2006;295:2158-63.

25 Lundström M, Stenevi U, Thorburn W. The Swedish national cataract register: a 9-year review. Acta Ophthalmol Scand 2002;80:248-57.

26 Jaycock P, Johnston RL, Taylor $\mathrm{H}$, et al. The cataract national dataset electronic multicentre audit of 55,567 operations: updating benchmark standards of care in the United Kingdom and internationally. Eye 2009;23:38-49.

$27 \mathrm{Ng}$ DT, Rowe NA, Francis IC, et al. Intraoperative complications of 1000 phacoemulsification procedures: a prospective study. J Cataract Refract Surg 1998;24:1390-5.

28 Singh R, Vasavada AR, Janaswamy G. Phacoemulsification of brunescent and black cataracts. J Cataract Refract Surg 2001;27:1762-9.

29 Jeganathan VSE, Robin AL, Woodward MA. Refractive error in underserved adults: causes and potential solutions. Curr Opin Ophthalmol 2017;28:299-304.
30 Mittra RA, Borrillo JL, Dev S, et al. Retinopathy progression and visual outcomes after phacoemulsification in patients with diabetes mellitus. Arch Ophthalmol 2000;118:912-7.

31 Squirrell D, Bhola R, Bush J, et al. A prospective, case controlled study of the natural history of diabetic retinopathy and maculopathy after uncomplicated phacoemulsification cataract surgery in patients with type 2 diabetes. $\mathrm{Br} J$ Ophthalmol 2002;86:565-71.

32 Romero-Aroca P, Fernández-Ballart J, Almena-Garcia M, et al. Nonproliferative diabetic retinopathy and macular edema progression after phacoemulsification: prospective study. J Cataract Refract Surg 2006;32:1438-44.

33 Brem H, Tomic-Canic M. Cellular and molecular basis of wound healing in diabetes. J Clin Invest 2007:117:1219-22.

34 Rayfield EJ, Ault MJ, Keusch GT, et al. Infection and diabetes: the case for glucose control. Am J Med 1982;72:439-50.

35 Zhang X, Beckles GL, Chou C-F, et al. Socioeconomic disparity in use of eye care services among US adults with age-related eye diseases: National health interview survey, 2002 and 2008. JAMA Ophthalmo/ 2013;131:1198-206.

36 Moss SE, Klein R, Klein BE. Factors associated with having eye examinations in persons with diabetes. Arch Fam Med 1995;4:529-34.

37 Behndig A, Montan P, Stenevi U, et al. Aiming for emmetropia after cataract surgery: Swedish national cataract register study. J Cataract Refract Surg 2012;38:1181-6. 